\title{
From Duverger to the Seat Product : seeking a pattern in pÿexperts evaluation of electoral systems
}

\section{Nemcok, Miroslav}

2021-07-03

pÿNemcok, M 2021 , ' From Duverger to the Seat Product : seeking a pattern in experts evaluation of electoral systems ' , Journal of Elections, Public Opinion and Parties , vol. 31 , no. 3 , pp. 408-422 . https://doi.org/10.1080/17457289.2019.1697880

http://hdl.handle.net/10138/333269

https://doi.org/10.1080/17457289.2019.1697880

acceptedVersion

Downloaded from Helda, University of Helsinki institutional repository.

This is an electronic reprint of the original article.

This reprint may differ from the original in pagination and typographic detail.

Please cite the original version. 


\title{
From Duverger to the Seat Product: Seeking a Pattern in Experts' Evaluation of Electoral Systems
}

\author{
Miroslav Nemčok \\ University of Helsinki \\ Masaryk University
}

\begin{abstract}
Widely influential Duverger's "law" and "hypothesis" describe the main direction of influence of electoral rules on party systems, however, their formulations are quite blurry what makes their application to concrete electoral results often ambiguous. Therefore, this research conducted an original survey among electoral experts $(n=131)$ to explore whether they apply Duverger's rule in a consistent pattern which could lead to its less ambiguous specification. Experts' responses revealed a considerable heterogeneity which indicates that they are often unsure about the likely outcomes of electoral systems. Nevertheless, experts were on average close to the central tendency predicted by the Seat Product Models (Taagepera, 2007) which quantifies the Duverger's rule. Hence, experts on average think that election outcomes should look like what Seat Product Models predict. Therefore, the Models should be used as a baseline in electoral studies, because they allow more fine-grained evaluation of electoral systems.
\end{abstract}

Keywords: electoral systems; experts; theoretical expectations; fragmentation; Seat Product

This article will be published in Journal of Elections, Public Opinion \& Parties (currently available as First View) 


\section{Introduction}

One of the most influential theoretical frameworks in the field of electoral studies is Duverger's "law" and "hypothesis". Generally, the Duverger's proposition can be summarized as: the more permissive the system is, the higher the resulting fragmentation of the party system will be (Duverger, 1963). Duverger described the main direction of influence of electoral rules on the resulting fragmentation of party systems, however, at its core, this widely applied expectation remained quite blurry. The only precisely defined element is that the seat allocation by plurality in single-seat districts should tend to produce two-party constellations. Yet, what kind of constellation is still acceptable as a result of restrictive systems, or how fragmented the outcome is expected to be in various kinds of more permissive systems remained unspecified.

Therefore, this research note examines the Duverger's rule and its application by experts on electoral systems to find out whether there is a general trend in the experts' assessments that could help to specify the expectations based on the Duverger's rule in a less ambiguous manner. This paper analyses responses of 131 experts in an originally conducted expert survey. Experts were requested to evaluate six cases of electoral results produced by simple systems and decide whether they could be considered as a typical outcome of given set of electoral rules.

This note discovers two relevant conclusions: First, experts' responses revealed a considerable heterogeneity. That indicates that, in many cases, experts remain uncertain about what the likely outcome of electoral systems should be. Second, despite heterogeneity among experts, their evaluation of electoral outcomes is close to what the Seat Product Models (Taagepera, 2007) predict to be the baseline central tendency for outcomes generated by given set of electoral rules. 
These findings point to the fact that even though electoral experts are undoubtedly well trained to see whether electoral results are surprising with respect to given electoral rules, there is no widely-accepted measure which would clarify Duverger's rule when it is confronted with empirical data. Nevertheless, this study suggests that experts have been dimly aware of the central tendency being close to what the Seat Product Models equations predict even before they were spelled out. Since the Models are expressed as mathematical formulas, they allow to formulate clear expectations about the baseline central tendency in the effects of electoral systems: to what degree can already a minor change in the number of seats appointed via an electoral system influence the number and size of political parties. Thus, they constitute a useful tool for increasing accuracy in electoral studies.

\section{Duverger and expectations about electoral outcomes}

In the field of electoral studies, the general expectation about the performance of electoral systems is most often derived from the "law" and "hypothesis" formulated by Duverger (1963) more than half a century ago. Duverger's law proposes that "the simple majority single-ballot system favors the two-party system" and this relationship holds so tightly in empirical reality that it led Duverger to conclude that "this approaches most nearly perhaps to a true sociological law" (Duverger, 1963: 217). Duverger's hypothesis assumes that "the simple-majority system with second ballot and proportional representation favors multipartyism” (Duverger, 1963: 239).

These two propositions became a foundation of the "Duvergerian agenda" (Shugart, 2005) in electoral research which generally expects that more restrictive systems (with FPTP being the purest form thanks to its SMDs) allow fewer parties to enter the assembly. On the contrary, their permissive counterparts (i.e., proportional systems with high district magnitude) result in a more heterogeneous and fragmented body (Rae, 1995). 
Even though Duverger captured the main direction of influence of electoral rules on the resulting fragmentation of party systems, the formulation of his widely applied law and hypothesis have remained quite vaguely specified until today. Indeed, it is clearly stated that the FPTP should lead to a two-party system, however, what constellation is still acceptable as a result of restrictive systems, or how fragmented outcomes should result from permissive systems remain a question.

Nevertheless, Duverger's framework became one of the most influential theoretical frameworks in the field of electoral studies (Shugart, 2005). It allows scholars to make reasonable assumptions about the effect of electoral rules on the number and sizes of parties getting representation in a system.

\section{Benefits of unambiguous theoretical frameworks}

Formulation of the Duverger's rule is in contrast with theories in other scientific disciplines such as physics, chemistry, or even economics (Colomer, 2007). Those apply less ambiguous specifications of theoretical concepts, ideally expressed as mathematical relationships, which capture approximate baseline tendencies typical for relationships among them. Similar practice can carry certain benefits also for political science.

First, the role of theories is to provide experts with sufficient expertise and accuracy so their evaluation of a similar problem can reach consistent conclusions (Weiss and Shanteau, 2004). If that is not the case, Cassidy and Buede (2009: 457-458) argue that "a principal reason for poor judgment is faulty beliefs, which are in turn related to a lack of adequate feedback, and an absence of robust, verified, and consistent theories". This aspect may not be fully apparent in political science, yet, one can hardly imagine that competing opinions among experts would be generally desired in medicine when two physicians evaluate the medical condition of a patient. Therefore, theoretical frameworks should provide a useful guidance for expectations about the studied effects. 
Second, more accurate specification of the theoretical frameworks allows to overcome directional approach which currently dominates the political science. Directional approach describes general tendencies, however, it does not allow to evaluate the relationships between concepts in a more fine-grained manner (Taagepera, 2018). For example, Duverger's rule allows to expect that a switch from FPTP to proportional system will likely increase the number of parties in a system, however, it does not provide much assistance to estimate at least a general tendency to what degree fragmentation increases if a proportional system increases the size of its districts.

Due to these reasons, political science should seek to capture the baseline central tendencies among studied concepts in a less ambiguous manner, despite complexity of social reality and abundance of factors influencing human behaviour.

\section{Quantification of Duverger's rule}

Relevant work in “quantification of Duverger's rule” has been done by Taagepera (2007). Even though Taagepera has successfully tested his below-discussed models against empirical data, the consistency of his work with perception of electoral experts has remained a question. This research aims to bridge these two aspects together.

Taagepera's (2007) core contribution is the Seat Product, which consists of only two institutional variables - country's average district magnitude $(M)$ and its assembly size $(S)$. Based on these two numbers, Taagepera develops quantitative logical models capable of estimating surprisingly accurate central tendencies for outcomes of electoral systems. Taagepera's models are expressed as mathematical formulas, therefore, their result is an exact numerical prediction which represents the expected outcome for given electoral system ( $\mathrm{Li}$ and Shugart, 2016: 26). It has to be emphasized that logical models do not claim to have the ability to perfectly estimate electoral outcomes. They just utilize the institutional constrains (i.e., number of available seats) and generate a prediction which serves as a benchmark or an 
expected central tendency for given institutional arrangements (Shugart and Taagepera, 2017: 113-114; Taagepera, 2018: 5).

Both Duverger and Taagepera begin at the institutional constrains of electoral rules and study their influence over the number and size of parties in a system. This conceptual overlap makes Taagepera's quantitative logical models a suitable theoretical quantification of the Duverger's rule and allows to compare the experts' application of the Duverger's logic against benchmarks predicted by the Models.

This paper utilizes two quantitative logical models developed by Taagepera (2007: 115-164) which describe the impact of electoral systems on two relevant attributes of party systems: largest part seat share, and effective number of parties. These two concepts suitably capture the format of a party system which constitutes the dependent variable in the Duverger's framework.

The first quantitative logical model predicts seat share of the largest party in an assembly $\left(\widehat{\mathrm{s}_{1}}\right)$. Even though Duverger's framework does not deal specifically with this attribute, size of the largest party has relevant implications for structure of a party system and its internal dynamics. This certainly falls under the focus of Duverger's theory. If the largest party is expected to gain more than 50 per cent of seats, such information reveals that the largest party can form the government (if the system is parliamentary) and thus become the dominant force in the future political development. Even when the value is lower than 0.5 (i.e., $50 \%), \widehat{\mathrm{s}_{1}}$ still gives a useful hint about the expected weight of the largest party in a system or how big could be the other parties.

The logical model specifies that the predicted largest party seat share $\left(\widehat{\mathrm{s}_{1}}\right)$ is equal to the inverse 8th root of the product of average district magnitude $(M)$ and assembly size $(S)$ :

$$
\widehat{s_{1}}=\frac{1}{(M S)^{1 / 8}}=(M S)^{-1 / 8}
$$


From this equation, Taagepera (2007: 152-156) takes another step and deduces a logical model estimating the effective number of parties with legislative representation $\left(\widehat{\mathrm{N}_{\mathrm{s}}}\right){ }^{1}$ The effective number of parties is a widely used indicator capturing the fragmentation of party systems. In fact, Duverger's law and hypothesis refer directly to this attribute when they predict that a specific electoral system will result in a "two-party system" or "multi-partyism" (Duverger, 1963: 217, 239).

The model estimating $\widehat{\mathrm{N}_{\mathrm{s}}}$ is equal to the sixth root of Seat Product:

$$
\widehat{\mathrm{N}_{\mathrm{s}}}=(M S)^{1 / 6}
$$

Due to the space constrains, this paper cannot discuss the comprehensive theoretical background for both models, however, it is provided in Taagepera's Predicting Party Sizes (2007: 115-164). ${ }^{2}$ Empirical testing revealed that quantitative logical models deliver remarkably good estimates of central tendencies: The statistical best fit lines are almost superimposed with the prediction lines for $\widehat{\mathrm{s}_{1}}$ and $\widehat{\mathrm{N}_{\mathrm{s}}}$ (Taagepera, 2007: 126, 153). Shugart and Taagepera (2017: 101-102) conducted additional empirical testing with extended dataset and found out that almost all electoral outcomes in hundreds of democratic elections worldwide remain within a factor of two $^{3}$ from the predicted values of $\widehat{s_{1}}$ and $\widehat{\mathrm{N}_{\mathrm{s}}}$. Even though this implies quite a bit of variation, the Seat Product Models provide an accurate benchmark of the underlying central tendency for the effects of electoral systems.

1. $\widehat{\mathrm{N}_{\mathrm{s}}}$ represents the effective number of parliamentary/seat-winning parties. For the formula see Laakso and Taagepera (1979).

2. Taagepera's logic is also effectively summarized by Li and Shugart (2016: 26-27) or Shugart and Taagepera (2018).

3. Factor of two means that the predicted value is multiplied or divided by two. 
Taagepera (2007: 23-46) originally warned that the Seat Product Models work satisfactorily only for simple electoral systems which allocate all seats in districts with average district magnitude $M$. In more complex systems, legal thresholds and adjustments outside the basic electoral districts blur the impact of $M$ and, therefore, additional parameters or other considerations are necessary. For two-tier systems, Li and Shugart (2016) and Shugart and Taagepera (2017: 285-307) presented a solution which accounts for the seats distributed via upper tier and hence improves predictions of the central tendencies based on the Seat Product Model.

\section{Data and methods}

The main goal of this work is to explore how experts on electoral systems utilize the Duverger's framework. As a benchmark, the research utilizes Taagepera's Seat Product Models and asks experts to evaluate the electoral outcomes in six cases that were intentionally selected for their large deviation from the prediction generated by the Seat Product Models. All cases represent simple electoral systems, as defined by Taagepera (2007: 23-46). Selection of deviating cases allows to keep the survey short and not too time-consuming for participating experts, while still being able to examine whether experts' evaluation is consistent with the quantitative logical models. Table 1 presents the list of included elections together with their expected and real values of effective number of parties and largest party seat shares. Additionally, it shows that the cases include various sizes of average district magnitude $M$ and assembly size $S$ what allows to evaluate experts' opinion across various electoral arrangements. 
Table 1. Selection of cases for expert survey

\begin{tabular}{|c|c|c|c|c|c|c|}
\hline & Assembly size $(S)$ & $\begin{array}{l}\text { Average district } \\
\text { magnitude }(M)\end{array}$ & $\begin{array}{l}\text { Effective number of } \\
\text { parties }\left(\mathbf{N}_{\mathbf{s}}\right)\end{array}$ & $\begin{array}{l}\text { Expected effective } \\
\text { number of parties } \\
\qquad\left(\widehat{N}_{s}\right)\end{array}$ & $\begin{array}{l}\text { Largest party seat } \\
\text { share }\left(s_{1}\right)\end{array}$ & $\begin{array}{c}\text { Expected largest } \\
\text { party seat share } \\
\left(\widehat{\mathbf{s}_{1}}\right)\end{array}$ \\
\hline Case 1: Luxembourg 1999 & 60 & 15 & 4.34 & 3.11 & $31.7 \%$ & $42.7 \%$ \\
\hline Case 2: Canada 2006 & 308 & 1 & 3.20 & 2.60 & $40.3 \%$ & $48.9 \%$ \\
\hline Case 3: Netherlands 2017 & 150 & 150 & 8.12 & 5.31 & $22.0 \%$ & $28.6 \%$ \\
\hline Case 4: Portugal 1991 & 230 & 10.45 & 2.23 & 3.66 & $58.7 \%$ & $37.8 \%$ \\
\hline Case 5: United Kingdom 1959 & 630 & 1 & 1.99 & 2.93 & $57.9 \%$ & $44.7 \%$ \\
\hline Case 6: Slovakia 2012 & 150 & 150 & 2.88 & 5.31 & $55.3 \%$ & $28.6 \%$ \\
\hline
\end{tabular}

Note: See Online appendix A for additional information on selected cases and Online appendix B for the questionnaire. 
The cases were anonymized, meaning that experts were presented only with necessary institutional variables, i.e., assembly size, number of districts and information on whether the system is majoritarian or proportional, and results for Party A, B, C, etc. used instead of real party labels. ${ }^{4}$ Participating experts were not informed that the presented electoral results are real. In fact, experts were provided with the same amount of information as is required by logical models to deliver a prediction of baseline central tendency.

In sum, 844 experts were approached whose (co-)authored contribution appeared in at least one of the two main journals dedicated to electoral research - i.e., Electoral Studies and Journal of Elections, Public Opinion, and Parties (JEPOP) - between January 2012 and October $2017 .{ }^{5}$ Selection of authors who were successful in convincing the reviewers and editors to pass their research articles through peer-review in the flagship journals allows this study to eliminate subjective bias which would be inevitable if the list of experts would be compiled by the survey administrator. Additionally, this selection method ensures that (a) the survey reached those scholars who are actively involved in the topic and (b) their work actively influence the development of the field. ${ }^{6}$ Data collection took place between October 16 and November 5, 2017, during which time the questionnaire was fully completed by 131 experts what is a number comparable to other survey among experts on electoral systems (see Bowler et al., 2005). Another 173 experts started to fill in the survey but gave up. Thirty-five

4. See Online appendix B for questionnaire.

5. All authors whose e-mail address was published on the journals' webpages were invited. In the case of Electoral Studies, authors of Election Notes were not approached.

6. It could be argued that this selection of survey respondents lumps together specialists on electoral systems and scholars more broadly focused on electoral behaviour. However, also broadly focused scholars publishing in Electoral Studies and JEPOP must consider permissiveness and (dis)proportionality of electoral systems - concepts built directly on Duverger's work. Therefore, their opinion is still a qualified assessment and provides relevant information on how experts in the field evaluate electoral systems and their outcomes. 
experts refused to participate and twenty-five were impossible to reach, despite a manual search for their new contact information.

For each of the six anonymized cases of election results, experts were asked two main questions: (Q1) for their opinion about fragmentation: "Imagine the most typical outcome of the [described system]. If you compare it with the displayed results, would you say that the resulting number of represented parties seem to be:" and (Q2) for their opinion about the largest party share: "Imagine the most typical outcome of the [described system]. If you compare it with the displayed results, would you say that the largest party seem to be:". Both questions offered the same set of answers, which were recoded into numerical values as follows (a) Too large =1; (b) As expected =0; (c) Too small = -1; (d) Hard to say = N/A. Every question offered experts an optional space to explain the reason(s) for given assessment.

\section{Measures}

The answers provided by experts are compared to the prediction of the central tendency for largest party seat share $\left(\widehat{\mathrm{s}_{1}}\right)$ and effective number of parties $\left(\widehat{\mathrm{N}_{\mathrm{s}}}\right)$. However, the experts were approached with a question whether they can spot a deviation from their idea of "the most typical outcome", while $\widehat{\mathrm{s}_{1}}$ and $\widehat{\mathrm{N}_{\mathrm{s}}}$ formulate a prediction which could be considered as "the most typical outcome". Hence, to achieve consistency, I need to construct a measure which would quantify the deviation of electoral outcomes in a given case from theoretical expectations based on $\widehat{\mathrm{s}_{1}}$ and $\widehat{\mathrm{N}_{\mathrm{S}}}$.

The biggest challenge for the measure is the fact that fragmentation of a party system as well as the share of a largest party can vary greatly. Therefore, one cannot apply basic subtraction to find out the absolute difference between expectation and outcome, because it does not take into account the qualitative difference between party system consisting of few 
and of many parties. For example, if an expectation is off by one party in case of a five-party system, it is still a decent estimation because it stays on the grounds of a multiparty constellation. However, in case of a two-party system being off by one party constitutes a much bigger failure, because it means that we are not talking about bipartisan system anymore. ${ }^{7}$ Therefore, instead of absolute differences (i.e., subtraction), which are unable to take variance in size into account, the indices employ relative differences reached through division.

In the indices $d_{N_{S}}$ and $d_{s_{1}}$ presented below, real electoral outcome (i.e., effective number of parties or largest party seat share) is divided by the theoretical prediction based on one of the logical models (i.e., $(M S)^{1 / 6}$ or $(M S)^{-1 / 8}$, respectively). The result represents the relative difference between a real electoral outcome compared to the expected central tendency. Additionally, a logarithm is applied on the result of the division. The reason is that it has been proven on numerous places (Taagepera, 2007: 115-164; Shugart and Taagepera, 2017: 101-108; Taagepera and Shugart, 1993) that the Seat Product (i.e., MS) reveals a linear pattern only on a logarithmic scale. The purpose of the logarithm is to straighten the trend of $d_{N_{S}}$ and $d_{s_{1}}$ into a linear form which is more intuitive and thus more consistent with experts' brief considerations while filling in the survey. The final formulas are as follows:

$$
\begin{aligned}
& d_{s_{1}}=\log \left[s_{1} /(M S)^{-1 / 8}\right] \\
& d_{N_{S}}=\log \left[N_{S} /(M S)^{1 / 6}\right]
\end{aligned}
$$

In theory, due to the implementation of the logarithm, the possible values of $d_{N_{S}}$ and $d_{s_{1}}$ can range from minus infinity to infinity. However, there are three arbitrary values which

7. Based on the widely accepted conceptual categories of party systems, I assume that experts evaluate resulting fragmentation in the similar fashion. 
can help grasp the meaning of a result. The first one is zero. If real and predicted values are equal, the result of their division is one. That, after the logarithm is applied, gives zero. Therefore, when $d_{N_{S}}$ or $d_{s_{1}}$ is equal to zero, the empirical outcome perfectly meets the expectation about baseline central tendency for given electoral system.

The second and third arbitrary chosen values of $d_{N_{S}}$ and $d_{s_{1}}$ are -0.3 and 0.3 . The value -0.3 signals that the actual outcome is half of the expected. On the contrary, if the empirical outcome is twice the expected, the value of the index is 0.3 . If a value falls within the interval $[-0.3,0.3]$, the real electoral outcome stays within a factor of two from prediction. ${ }^{8}$ These values are set with respect to the empirical testing conducted by Taagepera (2007: 123, 153) and Shugart and Taagepera (2017: 101-102) which revealed that most cases included in the datasets fall within this interval.

\section{Analysis: How experts evaluate outcomes of electoral systems}

In the survey, experts on electoral systems were requested to assess whether six presented election outcomes follow or deviate from the expected central tendency for described electoral rules. The descriptive statistics based on experts' responses are displayed in Table 2 . In all cases, the standard deviation is close to 0.5 . If we consider that experts were offered three options $-1,0$, and 1 , standard deviations of 0.5 suggest that evaluations done by experts are quite heterogeneous. Figure 1 visualizing the frequency of answers supports this conclusion. In most cases, three out of four provided answers (if we include the option "Hard to say") are chosen by a substantial number of respondents. Moreover, experts frequently opt for the "Hard to say"; even in the least ambiguous case (i.e., Case 5: United Kingdom 1959) every fifth expert chose this option. Such a large degree of heterogeneity can be explained by

8. Staying within a factor of two means that the result is within the interval bounded by numbers if the predicted value is multiplied or divided by two. 
the fact that political science does not have widely accepted standards that would unify expectations about outcomes of various electoral systems.

Table 2. Descriptive statistics of answers in the expert survey

\begin{tabular}{llrrrrr}
\hline & & N & Mean & Std. dev. & Min & Max \\
\hline Largest party & Case 1: Luxembourg 1999 & 93 & -0.075 & 0.472 & -1 & 1 \\
seat share & Case 2: Canada 2006 & 100 & -0.700 & 0.560 & -1 & 1 \\
& Case 3: Netherlands 2017 & 103 & -0.184 & 0.500 & -1 & 1 \\
& Case 4: Portugal 1991 & 99 & 0.465 & 0.644 & -1 & 1 \\
& Case 5: United Kingdom 1959 & 104 & -0.019 & 0.482 & -1 & 1 \\
& Case 6: Slovakia 2012 & 96 & 0.542 & 0.579 & -1 & 1 \\
\hline Effective & Case 1: Luxembourg 1999 & 99 & 0.101 & 0.580 & -1 & 1 \\
of parties & Case 2: Canada 2006 & 99 & 0.687 & 0.547 & -1 & 1 \\
& Case 3: Netherlands 2017 & 103 & 0.330 & 0.549 & -1 & 1 \\
& Case 4: Portugal 1991 & 94 & -0.245 & 0.651 & -1 & 1 \\
& Case 5: United Kingdom 1959 & 105 & -0.019 & 0.480 & -1 & 1 \\
\hline
\end{tabular}

This impression is additionally supported by the experts' responses to the optional space included in the survey in which they could voluntarily explain their assessment. It was used at least once by 87 out of the 131 participating experts who finished the survey. Surprisingly, only three experts (2.3\% of those who finished the survey) specifically mentioned a criterion they employed. Others (at least once) requested information about vote shares $(35$ respondents $=26.7 \%$ of those who finished the survey), additional features of electoral districts ${ }^{9}$ ( 25 respondents $=19.1 \%$ of those who finished the survey) or societal cleavages ( 6 respondents $=4.6 \%$ of those who finished the survey).

9. Namely institutional features, societal/demographic heterogeneity or district level party competition. 
Figure 1. The frequency of answers in the expert survey
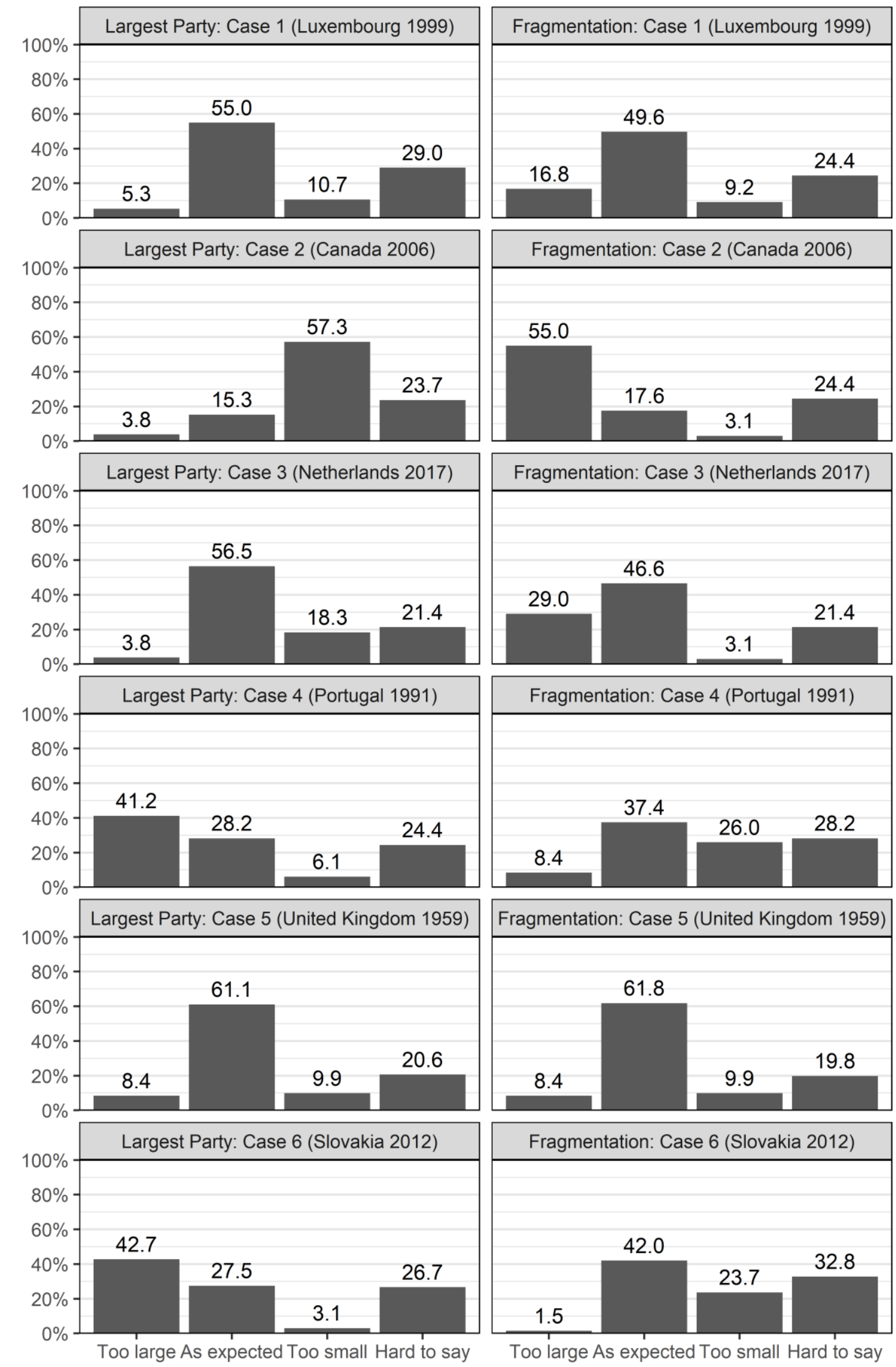
Based on the recoded answers of experts, I computed an average expert opinion about party system fragmentation for particular cases and plotted them against the deviation index for largest party seat share $d_{s_{1}}$ (see Figure 2). In the figures, the black line represents statistical best fit (based on results from Table 3).

Table 3. Statistical fit: Average of experts vs. deviation

\begin{tabular}{lcc}
\hline & \multicolumn{1}{c}{$d_{s_{1}}$} & $d_{N_{S}}$ \\
\hline $\begin{array}{l}\text { Average of experts: } \\
\text { Largest party seat share }\end{array}$ & $0.318^{* *} \quad(0.112)$ & \\
$\begin{array}{l}\text { Average of experts: } \\
\text { Effective number of parties }\end{array}$ & & $0.422^{*} \quad(0.159)$ \\
Constant & $0.042 \quad(0.046)$ & $-0.075 \quad(0.057)$ \\
\hline $\mathrm{N}$ & 6 & 6 \\
$\mathrm{R}^{2} /$ Adj. $\mathrm{R}^{2}$ & $0.669 / 0.586$ & $0.637 / 0.546$ \\
\hline Note: & & ${ }^{*} \mathrm{p}<0.1 ;{ }^{* *} \mathrm{p}<0.05$
\end{tabular}

The average expert opinion is in a high level of agreement with deviation index $d_{s_{1}}$. Despite having only six observations, the correlation is high $\left(\mathrm{R}^{2}=0.669\right)$ and statistically significant at $\mathrm{p}<0.05$ level. All cases lie close to the statistical best fit. In general, these results indicate that experts (on average) apply the Duverger's rule in the fashion similar to the estimation of its central tendency by the Model $\widehat{s_{1}}=(M S)^{-1 / 8}$.

However, Figure 2 reveals that while the three cases - Canada 2006, Netherlands 2017, and Luxembourg 1999 - deviate from the Seat Product Model to a comparable degree, the experts tend to see the differences among them as bigger. In the case of the 2006 Canadian elections, the experts tend to conclude that the seat share of $40.3 \%$ assigned to the largest party is too low for a FPTP system. This follows the Duverger's logic, which stipulates that 
such a system should produce a competition of two parties and hence the seat share of each party should not be too far away from 50\%. However, Duverger's (1963: 239) “proportional representation favors multi-partyism" does not provide much assistance to evaluate the size of the largest party in the Netherlands 2017 and Luxembourg 1999. That may be the reason why more than half of the experts concluded that the largest party is "As expected" in both cases. This indicates that even though experts can distinguish the instances when the largest party is too large or too small, the Duverger's rule is not clear enough to allow more fine-grained evaluation of electoral outcomes. Despite this aspect, the experts come fairly close to the baseline central tendency as predicted by the Seat Product Model.

Figure 2. Experts vs. Deviation: Largest party seat share

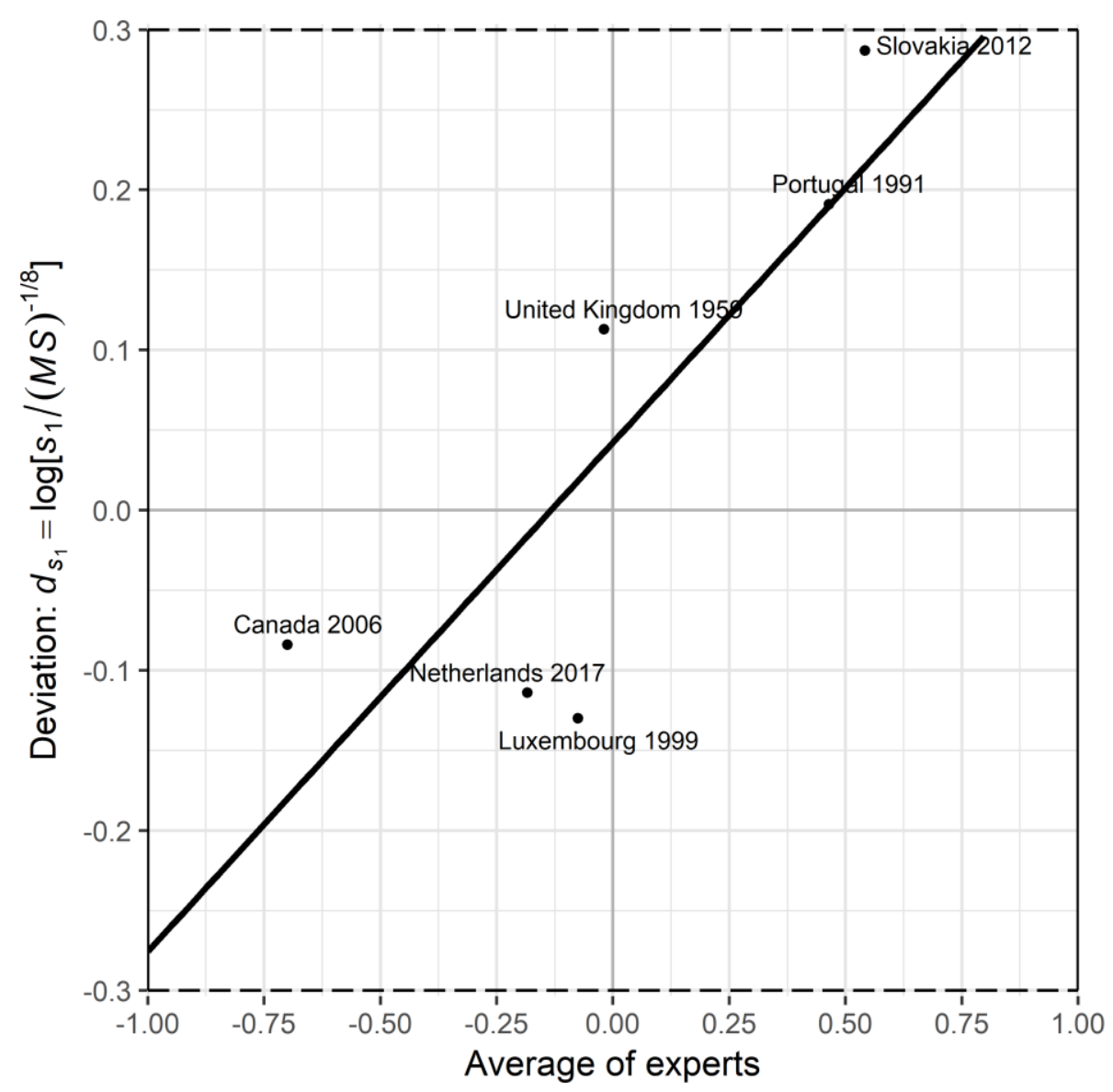


A very similar situation can be observed in the case of effective number of parties. The degree of agreement between the experts' average opinion and $d_{N_{S}}$ is again high $\left(\mathrm{R}^{2}=0.637\right)$ and despite limited number of observations, it is statistically significant at the $\mathrm{p}<0.1$ level (see Table 3). In fact, the actual $\mathrm{p}$-value is $\mathrm{p}=0.057$ and therefore this result only narrowly fails to pass the conventional threshold $\mathrm{p}<0.05$. Nevertheless, the evidence indicates that the experts' evaluation of election outcomes comes close to the expected benchmark based on Seat Product Model $\widehat{\mathrm{N}_{\mathrm{s}}}=(M S)^{1 / 6}$.

However, also in this case, the experts evaluate the resulting fragmentation (and its deviation from expected tendency) in Canada 2006, the Netherlands 2017, and Luxembourg 1999 slightly different than the Seat Product Model. The distribution of seats in the Canadian 2006 elections (i.e., 124-103-51-29-1) resulted in a party system constellation whose fragmentation was immediately rated by a majority of the experts as "Too large". Indeed, the actual effective number of parties is 3.22 , which makes Canada a poor representative of bipartisan system. Nevertheless, the experts chose "Too large" less frequently for the Netherlands 2017, where the effective number of parties climbs up to 8.12, and Luxembourg 1999 with effective number of parties equal to 4.34 despite implementing relatively small districts (i.e., 15 seats) together with a small assembly size (i.e., 60 seats). This again suggests that Duverger's framework provides a clear expectation for the FPTP, however, it is too vaguely formulated to provide a clear benchmark for proportional systems. Therefore, experts tend to choose "As expected" more often. 
Figure 3. Experts vs. Deviation: Effective number of parties

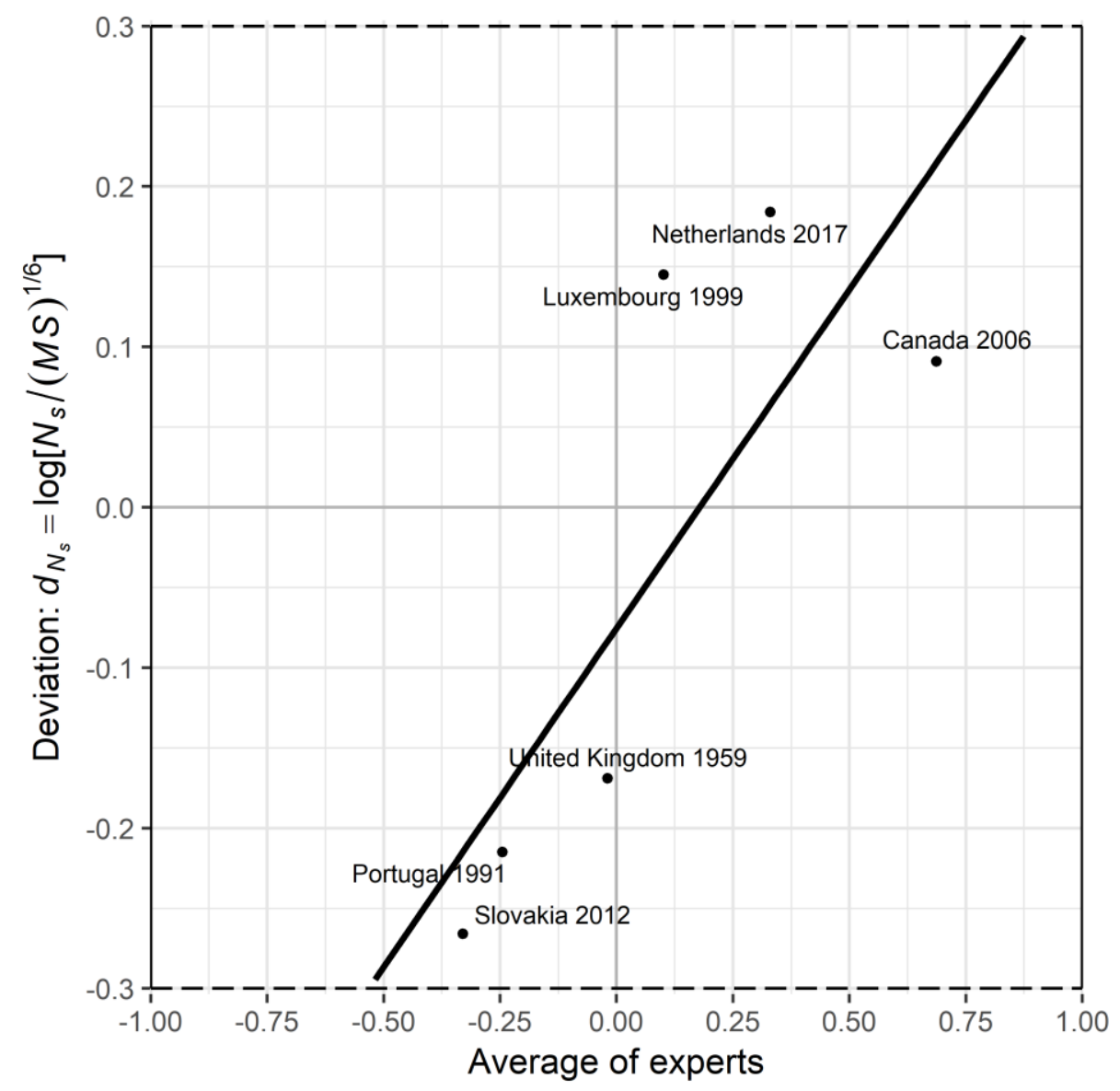

\section{Discussion and conclusions}

The Duverger's proposition (1963) stands at the very core of electoral studies. Even though this rule became widely influential (Shugart, 2005), its formulation has remained quite blurry until today. Therefore, this research conducted a survey among experts on electoral system $(\mathrm{n}=131)$ to find out how they utilize Duverger's framework.

Experts' responses revealed considerable heterogeneity and tendency to evaluate electoral outcomes “As expected”, if Duverger's framework does not provide a clear expectation about the effect of electoral rules. Nevertheless, the survey confirmed that when experts on electoral systems apply the Duverger's framework (1963), their assessment comes on average close to the baseline central tendency as estimated by the Seat Product Models 
(Taagepera, 2007). Hence, this research concludes that experts on average think that election outcomes should look like benchmarks generated by the Seat Product Models, however, a non-negligible share of them remain uncertain about what the likely outcome should be. Therefore, the experts seem to agree with the Seat Product Models that institutional constraints - average district magnitude $(M)$ and assembly size $(S)$ - partially determine election outcomes, yet there is no wide consensus whether (and which) additional factors should be taken into account in order to increase precision of political science in estimating effects of electoral systems. Nevertheless, unambiguous numerical estimation of the baseline central tendency generated by the Seat Product Models could provide a valuable tool for rigorous examination of the other factors. 


\section{References}

Bowler, Shaun, David M. Farrell, and Robin T. Pettitt. (2005) "Expert opinion on electoral systems: So which electoral system is 'best'?” Journal of Elections, Public Opinion \& Parties 15:3-19.

Cassidy, Michael F., and Dennis Buede. (2009) "Does the accuracy of expert judgment comply with common sense: Caveat emptor." Management Decision 47:454-469.

Colomer, Josep M. (2007) “What other sciences look like.” European Political Science 6:134-142.

Duverger, Maurice. 1963. Political Parties: Their Organisation and Activity in the Modern State. New York: Wiley.

Laakso, Markku, and Rein Taagepera. (1979) “'Effective’ Number of Parties: A Measure with Application to West Europe." Comparative Political Studies 12:3-27.

Li, Yuhui, and Matthew S. Shugart. (2016) "The Seat Product Model of the Effective Number of Parties: A Case for Applied Political Science.” Electoral Studies 41:23-34.

Rae, Douglas W. (1995) “Using District Magnitude to Regulate Political Party Competition.” Journal of Economic Perspectives 9:65-75.

Shugart, Matthew S. (2005) "Comparative Electoral Systems Research: The Maturation of a Field and New Challenges Ahead.” In: Michael Gallagher and Paul Mitchell (eds) The Politics of Electoral Systems. Oxford: Oxford University Press.

Shugart, Matthew S., and Rein Taagepera. (2018) "Electoral System Effects on Party Systems.” In: Erik S. Herron, Robert J. Pekkanen, and Matthew S. Shugart (eds) Oxford Handbook of Electoral Systems. Oxford: Oxford University Press.

Shugart, Matthew S., and Rein Taagepera. 2017. Votes from Seats: Logical Models of Electoral Systems. Cambridge: Cambridge University Press.

Taagepera, Rein. 2007. Predicting party sizes: the logic of simple electoral systems. New York: Oxford University Press.

Taagepera, Rein. (2018) "Science walks on two legs, but social sciences try to hop on one." International Political Science Review 39:145-159.

Taagepera, Rein, and Matthew S. Shugart. (1993) "Predicting the Number of Parties: A Quantitative Model of Duverger's Mechanical Effect." American Political Science 
Review 87:455-464.

Weiss, David J., and James Shanteau. (2004) "The Vice of Consensus and the Virtue of Consistency.” In: Kip Smith, James Shanteau, and Paul Johnson (eds) Psychological Investigations of Competence in Decision Making. Cambridge: Cambridge University Press. 